\title{
On the status of 'Maximize Presupposition'*
}

\author{
Sven Lauer \\ University of Konstanz
}

\begin{abstract}
Heim (1991) postulated the principle MAXIMIZE PRESUPPOSITION (MP), which has proven useful in the explanation of a range of phenomena. But what kind of principle is MP? Is it a normative constraint on language use, akin to a rule in a game? Or is it similar to Grice's MAXIMS OF CONVERSATION, which capture defeasible tendencies in behavior motivated by general considerations about cooperative communication? I argue that either construal faces significant challenges, and provide an alternative conception of MP as a 'linguistic preference'a (selfish) preference between linguistic forms that speakers happen to have. In this view, MP is neither a normative rule nor a Gricean maxim, but it functions like, and interacts with, such maxims in pragmatic reasoning.
\end{abstract}

Keywords: Maximize Presupposition, antipresupposition, felicity, implicature

\section{Introduction}

On standard assumptions, the items in the table below differ minimally in that the 'strong' item triggers a semantic presupposition that the 'weak' item lacks.

\begin{tabular}{ccl}
\hline strong item & weak item & differential presupposition \\
\hline the & a & uniqueness \\
both & every & domain contains two elements \\
know & believe & complement is true \\
\hline
\end{tabular}

For such pairs, we observe two kinds of pragmatic effects. First, in contexts where the presupposition in question is already part of the common ground, an utterance containing the weaker item is infelicitous. Second, in contexts where the presupposition is not part of the common ground, the use of the weaker form tends to implicate that the presupposition triggered by the stronger item is false (or not known to be true by the speaker). Both effects have been attributed to the pragmatic principle Maximize Presupposition (MP, originally postulated by Heim 1991), which, roughly speaking, exhorts speakers to more rather than less.

* I am grateful to Cleo Condoravdi, James N. Collins, Prerna Nadathur, Henk Zeevat, Kyle Rawlins, Sarah Zobel, Frank Sode, Hedde Zeijlstra and the audience at SALT for comments and discussion. This research was kindly supported by the EU FP7 Marie Curie Zukunftskolleg Incoming Fellowship Programme, University of Konstanz (grant no. 291784). This support is gratefully acknowledged. 
On the status of 'Maximize Presupposition'

\subsection{Some history: Heim 1991 on antipresuppositional requirements}

Heim (1991) was aiming to account for data like (1) and (2), noting that, intuitively, these sentences are not necessarily false, but always infelicitous (mißglückt, p. 514).

(1) \# A weight of the tent is $5 \mathrm{~kg}$.

(2) \# A sun is shining $c f$. The weight of the tent is $5 \mathrm{~kg}$.

$c f$. The sun is shining.

Heim briefly considered the option of explaining these infelicities as presupposition failure of a non-uniqueness presupposition carried by the indefinite determiner, but rejected this possibility in light of examples like (3) and (4).

(3) Robert caught a catfish that was 20 feet long.

does not presuppose: There is more than one 20-feet-long catfish.

(4) A nosy neighbor of mine broke into my attic.

does not presuppose: I have more than one nosy neighbor.

(3) and (4) can be felicitously uttered if the putative non-uniqueness presupposition is not part of the common ground; moreover, doing so would not trigger accommodation of such a presupposition. But the sentences would be infelicitous if the common ground entailed the uniqueness claims presupposed by the definite alternative. Evidently, it is sufficient for the felicity of (3) and (4) that these uniqueness claims are not part of the common ground. Heim formulates the following generalization:

Empirical generalization (Heim 1991: 515)

In utterance situations where the presupposition for ' $[$ the $\zeta] \xi$ ' is already known to be satisfied, it is not permitted to utter ' $[\mathbf{a} \zeta] \xi$ '.

I am going to refer to this effect as an 'antipresuppositional requirement'. ${ }^{1}$ Aiming to derive (5) from a more general principle, Heim notes that a derivation via Grice's (1975) Maxim of Quantity seems to be unworkable, and goes on to say:

"As fas as we can see, [(5)] can also not be derived from any of the other known Gricean maxims. Maybe we should postulate a new one: 'Presuppose as much as possible!'”

(Heim 1991: 515)

Sauerland (2003, 2008) dubbed this putative new maxim 'Maximize Presupposition' (henceforth, MP) and noted that the idea that a general principle is behind (5) is supported by the observation that the presuppositionally weaker members of various other pairs of expressions give rise to antipresuppositional requirements, as well. ${ }^{2}$

1 The term 'antipresupposition' was coined by Kai von Fintel (Percus 2006). I use 'antipresuppositional requirement' to distinguish the requirements Heim discussed from inferences a hearer may draw.

2 Besides the ones mentioned already, other items that have been argued to induce antipresuppositional requirements include French subjunctive morphology (Schlenker 2005), $\phi$-features (Sauerland, Andersen \& Yatsushiro 2005; Sauerland 2006) and tense morphology (Sauerland 2002). 
A principle like MP promises an attractive, uniform account of a range of phenomena. But its postulation raises two questions: First, how can Heim's natural language formulation be made more precise? Second, what should the status of the new principle be? While there is considerable work engaging the first question (Sauerland 2003, 2008; Percus 2006; Chemla 2008; Schlenker 2012; Leahy 2014), very little attention has been given to the second. ${ }^{3}$ Heim suggested that MP could be a 'Maxim of conversation' à la Grice (1975), i.e., a defeasible tendency in behavior, motivated by general considerations about cooperative communication. In Section 2 , I will point out that it is not at all clear that such a construal allows the principle to do the explanatory work we want it to do. Making matters worse, I will also show that an obvious alternative construal as a normative rule governing felicity is not viable either. In Section 3, I draw on recent advances in the formalization of Gricean reasoning to show that there is a viable construal of the principle, which differs from both the options discussed before. Before delving into these issues, however, I will briefly discuss another kind of effect that has been attributed to MP.

\subsection{Presuppositional implicatures and QUANTITY reasoning}

If the presuppositionally weaker member of a pair such as $\langle$ the, a $\rangle,\langle\mathbf{b o t h}, \mathbf{e v e r y}\rangle$ or $\langle\mathbf{k n o w}, \mathbf{t h i n k}\rangle$ is used in a context in which the presupposition of the stronger item is not part of CG, the weaker item is not only felicitous, but its use also tends to implicate that the presupposition of the stronger item is not true, or at least not known to be true by the speaker (whether the stronger implications are available depends in the usual way on an assumption that the speaker is taken to be opinionated and well-informed):

(6) a. Mary knows that Bill has a new boyfriend.

b. Mary believes that Bill has a new boyfriend.

$\rightsquigarrow \mathrm{Sp}$ is not certain that Bill has a new boyfriend.

$\rightsquigarrow$ Sp is certain that Bill does not have a new boyfriend.

$\rightsquigarrow$ Bill does not have a new boyfriend.

I am going to call these (potential) implications 'presuppositional implicatures'. In the past, antipresuppositional requirements and presuppositional implicatures have often been lumped together. ${ }^{4}$ This is often sensible, as the two phenomena do seem like two sides of the same coin, but in order to tackle the conceptual questions I am interested in here, it will be necessary to keep the two apart.

3 The exception is Schlenker (2012), who aims to reduce MP to Grice's MaXIM OF QUANTITY, denying the principle any independent status.

4 This is not true of Leahy (2014), from whom I borrow the term 'presuppositional implicature'. 
On the status of 'Maximize Presupposition'

Schlenker (2012) and Leahy (2014) argue convincingly that presuppositional implicatures can (at least in many instances) be explained as simple QUANTITY implicatures, without need for a separate principle like MP. As Schlenker (2012) reminds us, in a context in which neither $p$ nor its negation follows from CG, uttering a sentence that presupposes $p$ can inform the addressee that $p$ is true. That is, for example, a speaker who utters (6a) in a context in which nothing about Bill's relationship status is presumed can thereby inform her addressee that Bill has a new boyfriend. In the same context, (6b) would not convey this information. This is enough for standard QUANTITY reasoning to get off the ground, and deliver the implicature that the speaker is not certain that Bill has a new boyfriend. As Leahy (2014) puts it: "[... U]tterances can carry novel information via at least two vectors: through their assertive content and through informative presuppositions via accommodation. The maxim of quantity is rightfully silent about which vector one ought to employ in making our assertions usefully informative."

I agree with Leahy and Schlenker that if presuppositional implicatures were the only effects attributed to MP, we would not need to stipulate it as an independent pragmatic principle. But I think we ultimately need MP as an independent principle in order to account for antipresuppositional requirements. ${ }^{5}$ Hence the question remains: what kind of pragmatic principle should it be?

\section{Infelicity and obviations: A rock, and a hard place.}

Heim's original postulation suggests that MP is another 'maxim of conversation' in the style of Grice, i.e., a defeasible tendency in behavior motivated by general considerations about cooperative behavior. However, as we will see in Section 2.1, it is not quite clear that such a construal is viable.

An alternative construal suggests itself, however: Instead of taking MP to be Gricean maxim, we can instead take it to be a normative constraint, akin to a rule in a game. Such rules may seem exotic at first blush, but they are not. Virtually anyone who believes in the existence of semantic presuppositions, and takes them to impose requirements on the context of use implicitly assumes a rule like (7). ${ }^{6}$

\section{Presupposition rule}

If a sentence $S$ has a semantic presupposition $p$ then:

It is licit to utter $S$ only if $p$ is entailed by $C G$.

5 In this, I disagree with Schlenker, who also wants to attribute antipresuppositional requirements to the QUANTITY maxim. Space constraints prevent me from arguing this here, but I think his explanation ultimately fails in the cases where the effect of antipresuppositional requirements is most strikingviz., cases where the presupposition of the stronger item is part of entrenched world-knowledge.

6 The locus classicus for such a principle is Stalnaker 1973, 1974. 
This is the kind of rule that Lewis (1979) discussed, specifically what he called Specifications of correct play. In analogy with (7), we might formulate MP as the following antipresupposition rule:

\section{Antipresupposition rule}

If there are two otherwise equivalent sentences $S$ and $S^{\prime}$ such that $S$ has a semantic presupposition $p$ that $S^{\prime}$ lacks, then:

It is licit to utter $S^{\prime}$ only if $p$ is not entailed by $C G$.

Rules like (7) and (8) are quite different from Gricean maxims, on their usual construal: The former are normative requirements, specifying what is and is not licit behavior in language use. The latter are defeasible tendencies in behavior motivated by general considerations of cooperative communication. While both of these may be called 'pragmatic principles', whether we construe MP as one or the other will determine whether the principle can do the explanatory work we want it to do.

\subsection{Infelicity: trouble for the Gricean-maxim construal}

When a speaker violates an antipresuppositional requirement-e.g., if she utters $\mathbf{A}$ sun is shining under normal conditions - her utterance is infelicitous. At least prima facie, this basic fact speaks in favor of the normative-rule construal, and against the Gricean-maxim construal. Here is why.

On the normative-rule construal, a speaker who has violated an antipresuppositional requirement has violated a rule governing felicity, and the explanation of her utterance's infelicity is hence immediate. Things are different on the Gricean-maxim construal. Obvious failures to comply with Gricean maxims generally do not lead to infelicity. Instead, such failures either trigger implicatures (because they reveal that several maxims are in conflict in the context of use, or because the speaker has 'flouted' a maxim), or they will make the speaker appear uncooperative. But a lack of cooperativity need not (and generally does not) lead to infelicity. So on this construal, the mere fact that MP was (obviously) violated will not explain why the utterance is deemed infelicitous or odd.

\subsubsection{Infelicity via presuppositional implicature?}

On the normative-rule construal, presuppositional implicatures can be explained on the basis of antipresuppositional requirements, in the manner spelled out by Chemla (2008). But on the Gricean-maxim construal, it is tempting to reverse the order of explanation, and attempt to derive antipresuppositional requirements on the basis of presuppositional implicatures. 
On the status of 'Maximize Presupposition'

The idea would be the following: Presuppositional implicatures can be straightforwardly explained on the Gricean-maxim construal without recourse to antipresuppositonal requirements, in a fashion largely parallel (or, à la Schlenker/Leahy, identical) to QUANTITY implicatures. In contexts in which the presupposition is part of CG, this will lead to infelicity, not because the speaker violated a Gricean maxim, but rather because he implicates something that is incompatible with the common ground. Concretely, a speaker who utters A weight of the tent is $5 \mathbf{k g}$ would be taken to implicate, via Gricean MP, that the speaker is not certain that the tent in question has at most one weight. This implicature is patently false, as it is part of well-entrenched world-knowledge that tents have unique weights. The clash between implicature and world-knowledge creates the perceived infelicity.

But this line of reasoning is problematic, because Gricean conversational implicatures are traditionally considered optional enrichments. In virtue of their optionality, we do not expect such enrichments to ever lead to infelicity. Instead, if a possible enrichment is known to be false, it should simply not arise (and the implicature be 'suspended' or 'canceled by the context'). Indeed, influential Neo-Gricean theories like that of Gazdar (1979) straightforwardly predict that any mismatch between a potential implicature and the context will lead to the implicature being absent, rather than the utterance becoming infelicitous. Furthermore, many researchers consider this optionality to be a defining feature of Gricean implicatures. For example, Spector (2014: 19, emphasis mine) writes:

"[S]upplementing the Gricean approach with a specification that certain implicatures are obligatory does not seem consistent with the underlying conceptual motivation for the Gricean approach."

If the (widely-accepted) perspective articulated by Spector were correct (I will argue later that it is not), the explanation of antipresuppositional requirements via (Gricean) presuppositional implicatures would be blocked, because for this explanation to work, the implicatures in question must be obligatory.

\subsubsection{Infelicities: summary}

At least on traditional conceptualizations of Gricean maxims and conversational implicatures, the fact that obvious violations of MP lead to infelicity is an argument for the normative-rule construal, and against the Gricean-maxim construal. On the former, infelicity is directly explained as resulting from the violation of a rule. On the latter, this is not so, and the alternative option of explaining infelicity via a (Gricean) presuppositional implicature that is incompatible with the context would require the implicature in question to be obligatory, which goes against the traditional conception of such implicatures as optional enrichments. 


\subsection{Obviations: trouble for the normative-rule construal}

The considerations about infelicity in the previous section constituted only the first horn of a dilemma. Here is the second one: There are contexts where MP appears to be obviated, i.e., where it appears as if the principle does not apply. (9a), modelled after an example provided to me by an anonymous reviewer, is such a case. The indefinite a son is felicitous (and does not implicate non-uniqueness), even though nothing prevents the speaker from using the definite alternative in (9b) instead. ${ }^{7}$

(9) [The constitution of Phantasia stipulates: "A son of the king has to be present at the opening of the parliament". It is known to everyone that the current king has exactly one son, who is in attendance. The speaker is running through the regulations:]

a. As the constitution demands, a son of the king is present, ...

b. As the constitution demands, the son of the king is present, ...

Other cases where MP is obviated can be constructed by having the less-presupposing form be mentioned in the nearby discourse:

(10) $A$ : Has Mary submitted the grades for all students in her seminar?

$B$ : How many people took it for credit?

$A$ : [looks it up] Just two.

$B$ : I see two grades. So she has submitted the grades for all students.

Again, B's final utterance could just as well have been (11).

(11) $B$ : I see two grades. So she has submitted the grades for both (students).

In both cases, the utterance of the less-presupposing form is felicitous even though the presupposition of the stronger competitor is part of the common ground. Intuitively, the reason is clear: In (9a), the indefinite is fine because its use serves the purpose of maintaining parallelism with the text of the law, in (10), all is fine because $B$ 's statement is a response to a question that was asked with all.

Such obviations are entirely expected on the Gricean-maxim construal, but not on the normative-rule construal. If MP is Gricean maxim, it is expected that it 'trades off' with other pragmatic pressures (such as a desire to be parallel to the text of the law or a nearby utterance). But on the normative-rule construal, such obviations are

7 Kyle Rawlins (p.c.) raises the question whether (9a) is a true case of obviation, since it is possible that the definite in (9b) is an instance of the 'possessive weak definites' discussed in Barker 2005 and Rawlins 2005, 2006, which lack uniqueness implications. This worry is well-founded, esp. since Alonso-Ovalle, Menéndez-Benito \& Schwarz (2011) show that whether MP-effects with indefinites obtain depends in the expected way on whether the use of definite competitor would imply uniqueness. (10) is immune to this worry, as it does not involve a definite competitor. 
On the status of 'Maximize Presupposition'

extremely puzzling. Why should the fact that the speaker is trying to be parallel to another utterance or the text of the law have any influence on whether the rule in (8) applies? On the normative-rule construal, obviations are entirely unexpected and it is unclear how we could accommodate them, except by adding ad hoc exception clauses to the statement of the rule, which is obviously undesirable.

\subsection{Infelicities and obviations: Summary}

A Gricean-maxim construal can easily deal with obviations of MP, but it is unclear how it can predict that obvious violations of the principle lead to infelicity in many cases. Conversely, a normative-rule construal straightforwardly predicts infelicities, but it is hard to see how it could account for obviations. Unless this tension can be resolved, there is no viable construal of MP that accounts for all the facts.

\section{Towards a viable (Gricean) conception of MP}

MP initially seemed to offer an attractive, uniform and parsimonious account of a range of empirical phenomena. Was this explanatory success a mirage? Do we have to abandon the principle and seek other explanations for antipresuppositional requirements and presuppositional implicatures? I am going to argue that we do not. There is a workable conception of MP, which is broadly Gricean in nature, but which still can predict infelicities where we find them. I will argue (see also Lauer 2013, 2014), that the existence of obligatory implicatures is not conceptually incompatible with a Gricean approach. Indeed, a number of recent formalizations of Gricean reasoning make us expect the existence of obligatory implicatures in certain, well-defined circumstances, and they also make us expect that such obligatory implicatures lead to infelicity when they are known to be false. And yet, obviations will fall out of the system naturally.

\subsection{Optimization-based theories of pragmatic inference}

The class of theories of pragmatic inference that I have in mind are ones that one might call 'optimization-based' theories, which include recent game-theoretic theories, in particular those in the Iterated Best Response (IBR) tradition (Jäger 2007; Franke 2009; Degen \& Franke 2012), as well as the closely related Rational Speech Act model (Frank \& Goodman 2012; Bergen, Goodman \& Levy 2012; Potts \& Levy 2015; Potts, Lassiter, Levy \& Frank 2015), and (if appropriately construed) bidirectional optimality-theoretic theories (Blutner 2000: et seq.), as well as the Dynamic Pragmatics of Lauer (2013). What these theories have in common is that they faithfully model Gricean pragmatic inference as reasoning about utterance 
choice. ${ }^{8}$ As such, they share a common structure: They feature a representation $B$ of (speaker) beliefs, a representation of (speaker) preferences $P$ and a function $\mathrm{Opt}_{B, P}(\mathscr{A})$, which selects the 'best' utterance action(s) from a set of alternatives $\mathscr{A}{ }^{9}$ Then, they take the hearer to assume that the speaker uses Opt to decide which utterances to make. As a consequence, by observing an utterance $\phi$ the hearer learns that $\phi$ was 'best' according to the speaker's $B$ and $P$, which enables inferences about what $B$ and $P$ must be like. These inferences are the implicatures.

\subsubsection{Preferences vs. maxims}

Most optimization-based theories omit any direct mention of conversational maxims, whose role is instead played by the speaker's preferences. One reason for this is that this makes the accounts more general. Maxims can simply be construed as a special kind of preference, viz., those preferences that speakers happen to have frequently because they follow from general considerations of cooperative behavior. But not every preference that influences a speaker's choice of utterance will be of this kind. Some speaker preferences will not be motivated by general considerations about cooperative behavior. And such preferences can be selfish, in which case they can be active even in contexts in which little or no cooperativity can be assumed. Both these features will be instrumental in enabling a Gricean account of MP.

\subsubsection{Basic set-up}

In what follows, I will use the system of Dynamic Pragmatics (Lauer 2013), but I believe all of the mentioned optimization-based theories could accommodate the kind of implicature I derive here, and hence enable a Gricean conception of MP. To demonstrate the basic workings of the system I am going to sketch how to derive a basic ('primary') quantity implicature in Dynamic Pragmatics. Such implicatures involve two types of preferences. The first is a preference I call SINCERITY. ${ }^{10}$

8 In this respect, optimization-based theories (favorably) contrast with 'generative' theories in the style of Gazdar (1979), which are often called 'Neo-Gricean'. The latter kind of theory is (roughly and informally) motivated by appeal to reasoning about (cooperative) utterance choice, but this reasoning remains entirely unmodeled in the system itself. The theories developed by another notable 'Neo-Gricean', Larry Horn (1972, 1984, 1989, 2000: a.o.), arguably are (informal versions of) 'optimization-based' theories, as is the 'intention-based' approach to implicature in Geurts 2010.

9 This kind of setup should be familiar from the models of action choice employed in decision and game theory. Some, but not all, of the theories mentioned in the text use a classical Bayesian set-up- $B$ is s probability distribution, $P$ is a numerical utility assignment, Opt maximizes expected utility.

10 SINCERITY (which bears an obvious resemblance to Grice's QUALITY maxim) can be further motivated by assuming that speaker becomes committed to the asserted and presupposed content of his declarative utterances, and that speakers generally prefer not to be committed to propositions they 
On the status of 'Maximize Presupposition'

\section{SINCERITY}

a. is violated iff: the speaker utters a declarative sentence whose asserted or presupposed content she does not believe to be true.

b. is satisfied otherwise.

The second kind of preference is schematic. For a given sentence $X$ :

(13) INFORM $X$ :

a. is violated iff: the speaker believes $X$, but the addressee does not.

b. is satisfied otherwise.

Instances of INFORM $X$ essentially represent conditional preferences: if the speaker takes $X$ to be true, she wants the hearer to believe $X$, as well. A speaker will have such a preference in a given context if she takes $X$ to be relevant information to convey to her audience in that context. Instances of INFORM $X$ hence play the role of Grice's QUANTITY and RELATION maxims.

I assume that such preference are ranked in terms of how important they are for the agent, and - for expository purposes-assume a very simple Opt-function: The preferences are evaluated 'lexicographically', i.e. the highest-ranked preferences are taken into account first, and only if those do not make a decision between two utterances, the lower-ranked preferences come into play. This allows us to display the outcome of the decision procedure in a very simple, familiar format—viz., tableaus in the style of classic Optimality Theory (Prince \& Smolensky 1993). In these tableaus, the preferences of the speaker take the place of the constraints, while alternative utterance actions takes the place of the candidates. ${ }^{11}$

\subsubsection{A basic quantity implicature}

With this set-up in place, here is how we derive the implicature in (14).

Some of the students came to the party.

$\rightsquigarrow S p$ is not certain that all students came to the party.

do not believe.

11 I want to emphasize that I use OT tableaus solely as a familiar and convenient way to display the outcome of a lexicographic decision procedure. In particular, no OT-like claim is made that the preference I postulate are drawn from a set of universal constraints, or anything of the kind. Quite to the contrary: Which preferences an agent has (and how they are ranked) will vary widely from context to context, and in many cases, hearer-uncertainty about what preferences the speaker has will play a deciding role. Likewise, the candidates here are alternative utterance actions, not linguistic forms, and a form being non-optimal (given the preferences the speaker has in a context) simply means that it is not the best way to satisfy the speaker's preferences, not that this form is 'ruled out' or ungrammatical, or anything like that. 
I make the standard assumption that the sentence in (14), abbreviated as some, competes pragmatically with All of the students came to the party, abbreviated as all. To keep things maximally simple, I assume that (the hearer believes that) the speaker has only three preferences: SINCERITY, INFORM all and INFORM some, and that SINCERITY is ranked above the INFORM $\cdot$ preferences. $^{12}$ Finally, I restrict attention to contexts where it is commonly assumed that the addressee will come to believe the content of the speaker's utterances. ${ }^{13}$

With these assumptions, which form is optimal for the speaker $S p$ will depend on whether $S p$ believes all to be true: Figure 1(a) shows the outcome of the decision procedure in case $S p$ believes some, but not all. Uttering some is optimal in this case, but uttering all is not, as doing so would violate SINCERITY. If, by contrast, $S p$ believes some and all to be true, then uttering all will be optimal (Figure 1(b)), since neither action violates SINCERITY, but only all satisfies INFORM all. ${ }^{14}$

\begin{tabular}{|c|c|c|c|}
\hline$\neg \mathrm{BEL}_{S p}($ all $)$ & SINCERITY & INFORM ALL & INFORM SOME \\
\hline \hline all & $*$ & & \\
\hline some & & & \\
\hline
\end{tabular}

(a) $S p$ believes some, but not all

\begin{tabular}{|r|c|c|c|}
\hline $\mathrm{BEL}_{S p}($ all $)$ & SINCERITY & INFORM ALL & INFORM SOME \\
\hline \hline all & & & \\
\hline some & & $*$ & \\
\hline
\end{tabular}

(b) $S p$ believes all (and some)

Figure 1 Decision outcomes for the scalar implicature of some.

Prior to $S p$ 's utterance, the addressee $A d$ will be uncertain as to whether $S p$ believes all, and hence we can model Ad's information state as a set of possible worlds which contains some worlds in which $S p$ has this belief, and others in which she does not. Since $A d$ believes that $S p$ uses Opt to choose her utterance, in all worlds in $A d$ 's belief state in which $S p$ believes all, $S p$ will utter all, while in worlds in which $S p$

12 Of course, the assumption that a speaker has only these three preferences is highly artificial. But it can be replaced, without affecting the explanation, with the assumption that the speaker has no other preferences that make a difference for the candidates we are looking at.

13 For asserted content, this assumption can be reduced to the assumption that the addressee takes the speaker to be trustworthy and well-informed. For presupposed content, the same is true on a conception of presupposition as the one in Mandelkern (2016), where presuppositions are just another kind of entailment. If presuppositions are instead taken to impose constraints on input context (modulo accommodation), the assumption for presupposed content is essentially Chemla's (2008) 'speaker authority'.

14 I simplify here by assuming that all entails some (which it will contextually if the domain is presumed to be non-empty), and by only considering worlds in which $S p$ believes at least some. In full generality, we want to also take into account that, prior to $S p$ 's utterance, the hearer will typically not know whether $S p$ believes some. If she does not, some and all will be equally (non-)optimal, and to make the correct prediction that (the hearer assumes that) $S p$ would not utter either form in this case, we would need another utterance alternative, such as a null-utterance. 
On the status of 'Maximize Presupposition'

does not believe all, $S p$ will utter some.

When $A d$ observes $S p$ 's utterance of (14), Ad learns that the actual world is one of those in which $S p$ chose some. We model this by updating $A d$ 's belief state, eliminating all worlds in which $S p$ does not utter some. Given current assumptions, this leaves $A d$ with a belief state that contains only worlds in $S p$ does not believe all to be true. That is, observing an utterance of some will result in $A d$ believing that $S p$ does not believe all. This is precisely the implicature we set out to model. ${ }^{15}$

\subsection{A digression on disjunction: Brevity}

Here is another case of quantity reasoning, albeit a more contextual one:

(15) $\quad[A$ and $B$ are in Konstanz, Germany, talking about where their various acquaintances are, to figure out whether they can meet up with any of them on their upcoming US trip.]

$A$ : Where is Sven?

$B:$ He's in the US.

In this context, $B$ 's utterance likely implicates that $B$ does not know where in the US Sven is. This implicature is modeled as before-all that changes is that He's in the US takes the place of some and an utterance about a more specific location (e.g., He's in Austin) takes the place of all.

In both cases, it is crucial that we assume an INFORM-preference for the form with the stronger meaning (all or Austin, respectively). If this preference were not in place, both utterance alternatives would be equally optimal regardless of whether the speaker believes in the stronger one, and hence, no implicature would be generated. This a good prediction: If we change the context such that Sven's precise location is irrelevant in case he is in the US, the implicature vanishes:

(16) $\quad[A$ and $B$ are in Konstanz, Germany, planning a dinner party on the same day. They are trying to figure out who to invite.]

$A$ : Is Sven in town?

$B:(\mathrm{No}$,$) he's in the US.$

Now consider the example in (17). In the context of (15), this sentence will implicate that $B$ does not know that Sven is in Austin, and that he does not know that Sven is in Stanford. This is unsurprising, as the the disjunction is informationally weaker than both disjuncts, and the context in (15) is such that the extra information is relevant (hence we can assume both INFORM Austin and INFORM Stanford preferences). But now consider (17) in the context in (16). In this case, the implicature survives, even though the extra information provided by He's in Austin is not relevant!

15 Stronger implicatures will arise under suitable contextual conditions, see Lauer 2013: §9.2.3. 
What is going on? Following Eckardt (2007), I want to suggest that the difference between the two cases is that there is an additional preference at play in the case of disjunction. This additional preference, which I am going to call BREVITY, is a preference for shorter, less complex expressions, which is familiar in a Gricean setting as a sub-maxim of the MAXIM OF MANNER. I am going to assume that this preference is in place, and ranked below SINCERITY.

The crucial case to investigate is one where the speaker believes Austin (the case where she believes Stanford is symmetric). Figure 2(a) shows the decision in case the speaker has an additional preference INFORM Austin (corresponding to the context in (15)), while 2(b) shows the decision in case the speaker does not have such a preference (corresponding to the context in (16)).

\begin{tabular}{|c|c|c|c|}
\hline $\mathrm{BEL}_{S p}($ Austin) & SINCERITY & INFORM Austin & BREVITY \\
\hline \hline Austin & & & \\
\hline Stanford & $*$ & $*$ & \\
\hline Austin or Stanford & & $*$ & $*$ \\
\hline
\end{tabular}

(a) With INFORM Austin

\begin{tabular}{|c|c|c|}
\hline $\mathrm{BEL}_{S p}$ (Austin) & SINCERITY & BREVITY \\
\hline \hline Austin & & \\
\hline Stanford & $*$ & \\
\hline Austin or Stanford & & $*$ \\
\hline
\end{tabular}

(b) Without INFORM Austin

Figure 2 Decisions in worlds where the speaker believes Austin.

Due to BREVITY, the decision is the same in both cases: Austin is more optimal than Austin or Stanford. ${ }^{16}$ In the absence of other preferences, the (more complex) disjunction will be optimal only in worlds in which the speaker believes neither Austin nor Stanford. This is why the use of the disjunction will reliably imply speaker ignorance, regardless of whether the extra information that would be contributed by uttering the individual disjuncts is relevant.

\subsection{Outcome vs. linguistic preferences, and 'Need A Reason' implicatures}

The INFORM preferences and the BREVITY preference differ conceptually in an important way: A preference for conveying a piece of information is a preference about the consequences of utterances. We may call this an 'outcome preference'. BREVITY, by contrast, is a preference between linguistic forms. We may call this

16 Spelling out the BREVITY preference formally requires a different format than that for preferences like SINCERITY and INFORM $X$, since BREVITY must compare the different forms (it is analogous to markedness constraints in OT). See Lauer 2013 for one way to do this. In frameworks that use numerical utilities, these kinds of preferences are usually modelled via action-specific costs that are subtracted from the (outcome-)utility of the action. 
On the status of 'Maximize Presupposition'

a 'linguistic preference'. The two kinds of preferences differ in a number of ways. Outcome preferences are context dependent: What a speaker takes to be relevant information will vary from context to context. In addition, outcome preferences will often depend on an assumption of cooperativity: Only a cooperative speaker will want to convey all relevant information, a non-cooperative speaker may not. Linguistic preferences, by contrast, are not context dependent in the same way: which of two forms is shorter or less complex does not depend on the context of use. And linguistic preferences can easily be construed as selfish. It is plausible to assume that a speaker always prefers not to produce unnecessarily long and complex linguistic forms, even when the interests of speaker and hearer are not aligned.

As a consequence, it is plausible to assume that a speaker always has the BREVITY preference. ${ }^{17}$ If we assume, in addition, that the individual utterances $A$ and $B$ are always considered as possible utterance alternatives to $A$ or $B$, then, whenever a speaker utters $A$ or $B$, she must have some preference which (i) dominates BREVITY and (ii) is satisfied by $A$ or $B$, but not by the disjuncts. And the inference that such a preference is present will arise obligatorily in an optimizationbased system: Without such a preference, the uttered form cannot be construed as 'optimal'. 18

This pattern of reasoning is fully general, and not limited to the BREVITY preference. Obligatory Gricean inferences will be expected whenever the conditions in (18) are met. For obvious reasons, I refer to these inferences as Need a Reason (NaR) implicatures.

The use of an expression $e$ will trigger a mandatory NaR implicature if:

i. there is another form $e^{\prime}$ which is not semantically weaker.

ii. there is a ceteris paribus preference favoring $e^{\prime}$ over $e$ that is present in all contexts.

iii. use of $e$ automatically makes $e^{\prime}$ salient as an alternative.

If one form is always preferred over another, everything else being equal, then the use of the dispreferred form will be a reliable signal that everything else is not equal. That is, in case the dispreferred form is used, there must be some other preference (the 'reason') which defeats the ceteris paribus preference for $e^{\prime}$.

Thus optimization-based theories predict the existence of certain 'obligatory implicatures'. Far from being 'incompatible with the underlying conceptual motivation for the Gricean approach' (as Spector 2014 put it), the existence of obligatory

17 But it will usually be ranked below his outcome preferences-with the possible exception of cases like Twitter messages or the telegrams of old.

18 In cooperative contexts, something like SINCERITY will often be the only plausible candidate for the 'defeating preference', which is why in such contexts, the use of disjunction fairly reliably implicates speaker ignorance. 
implicatures follows naturally from a truly Gricean understanding of pragmatic reasoning as reasoning about why the speaker chose the utterance he made.

\subsection{MaXimize Presupposition as a linguistic preference}

Recall from Section 2.1.1 that a Gricean construal of MP that aims to account for infelicities via presuppositional implicatures has to assume that these implicatures are obligatory. It hence should come no surprise that I propose to fit MP into the system as a 'linguistic preference'-i.e., a (selfish) preference that favors certain forms over others.

But which forms does it favor? Heim's (1991) formulation 'Presuppose as much as possible!' suggests that the MP preference should favor a sentence $S$ over $S^{\prime}$ if the semantic presupposition of $S$ are strictly stronger than those of $S^{\prime}$. However, Percus (2006) pointed out that a comparison of global semantic presuppositions is not enough. He provides pairs of sentences like the one in (19). On standard assumptions about presupposition projection, the two sentences are presuppositionally equivalent, because the presupposition of both in (19a) is filtered out by its environment. This means that if MP is formulated in terms of global semantic presuppositions, the principle will not favor one of these sentences over the other. And yet, (19a) is felicitous but (19b) is not.

a. $\checkmark$ Everyone with exactly two students assigned the same exercise to both of his students.

b. \# Everyone with exactly two students assigned the same exercise to all of his students.

If this contrast in felicity is to be explained in the same way as standard cases of antipresuppositional requirements, then MP must be formulated in a more local manner. Here, I preliminarily adopt Percus' solution to this problem (the formulation is taken from Collins 2016):

(20) Lexical MP preference (after Percus 2006)

Given a lexical scale $\langle\alpha, \beta\rangle$, a sentence $S$ containing the presuppositionally stronger lexical item $\alpha$ is always preferred to the alternative sentence $S^{\prime}$ containing the lexical item $\beta$ in place of $\alpha$.

It should be obvious that (20) will prefer (19a) over (19b), even though the two have the same overall presuppositions: (19b) contains all in place of both, which has a stronger lexical presupposition. 
On the status of 'Maximize Presupposition'

\subsubsection{Deriving a presuppositional implicature}

If we assume that the MP preference (like BREVITY) is present in all contexts, and that use of a form makes its presuppositional alternatives salient as alternative utterances the speaker could have made instead, we predict presuppositional implicatures as NaR implicatures. Concretely, consider a standard case of such an implicature:

Bill has a new boyfriend.

(abbrev. as boyfriend)

(22) Mary knows Bill has a new boyfriend.

(abbrev. as know)

(23) Mary believes Bill has a new boyfriend.

(abbrev. as believe)

$\rightsquigarrow S p$ does not believe that Bill has a new boyfriend.

Assuming the speaker has the three preferences SINCERITY, MP and BREVITY, the outcome of the decision procedure in the relevant cases is given in Figures 3(a) and 3(b). ${ }^{19}$ Since believe is only optimal if know violates SINCERITY, we predict the presuppositional implicature.

\begin{tabular}{|r|c|c|c|}
\hline $\mathrm{BEL}_{S p}$ (boyfriend) & SINCERITY & MP & BREVITY \\
\hline \hline believe & & $*$ & \\
\hline know & & & \\
\hline
\end{tabular}

(a) $S p$ believes boyfriend.

\begin{tabular}{|r|c|c|c|}
\hline$\neg \mathrm{BEL}_{S p}$ (boyfriend) & SINCERITY & MP & BREVITY \\
\hline \hline believe & & $*$ & \\
\hline know & $*$ & & \\
\hline
\end{tabular}

(b) $S p$ does not believe boyfriend.

Figure 3 Decisions for a basic presuppositional implicature.

\subsubsection{Infelicity}

In general, use of the weaker element of a pair of presuppositional alternatives will give rise to the implicature that there is a preference that (i) dominates MP and that (ii) is satisfied by the weaker element, but not by the stronger one. In many contexts, SINCERITY is the only plausible candidate, and hence we derive the inference that the speaker is not certain that the presupposition of the stronger element is true.

Now consider what happens if the presupposition of the sentence containing the stronger element is part of entrenched world-knowledge (or otherwise saliently in the common ground), or if the presupposition is trivialized or filtered away (as in Percus' (19a)). In these cases, SINCERITY cannot distinguish between the two alternative

19 Things would not change, of course, in case we also include an INFORM boyfriend preference, as on the Schlenker/Leahy account of presuppositional implicatures. In that case, the optimality of know in case the speaker believes boyfriend would happen to be overdetermined, as know satisfies both preferences better than believe in this case. 
utterances, and neither can any other outcome preference based on informativity (such as an uncooperative preference to withhold information). I want to suggest that, in many such cases, there simply will be no plausible preference that can be made responsible for the speaker's use of the alternative that is dispreferred by MP. Hence, use of this alternative cannot be construed as 'optimal'. Formally, given the assumption that the speaker will only make 'optimal' utterances, updating with the information that the speaker uttered a form that is optimal in no world in the hearer information state will result in an empty (absurd) information state. This is arguably sufficient to predict the infelicity of violations of antipresuppositional requirements like \#A weight of the tent is $5 \mathrm{~kg}$.

\subsubsection{Obviation}

Now consider a case of obviation, (10) from Section 2.2, repeated below.

(10) $A$ : Has Mary submitted the grades for all students in her seminar?

$B$ : How many people took it for credit?

$A$ : [looks it up] Just two.

$B:$ I see two grades. So she has submitted the grades for all students.

In $B$ 's final utterance, all competes, as usual, with both. Furthermore, the presupposition of both would not be filtered away, and it is saliently part of the common ground ( $A$ has just asserted the content of the presupposition, and has not been challenged). So, as before, SINCERITY cannot be the preference that motivated the use of all, which is dispreferred by MP. And yet, $B$ 's utterance is felicitous.

I want to account for this as follows: Even though no preference based on informativity (like SINCERITY) could make a difference here, there is a plausible preference the speaker may have that is satisfied by all but not by both: The utterance with all will maintain parallelism between $B$ 's utterance and $A$ 's initial question. If this preference is ranked above MP, then $B$ 's utterance will be optimal. ${ }^{20}$

We predict that antipresuppositional requirements are obviated in any context where there is a plausible preference that defeats MP. Such a preference will be more difficult to come by if the presupposition triggered by the stronger form is part of entrenched world-knowledge (or blocked or filtered away). In the examples of obviation I have given in this paper, the MP-defeating preference has always been one for a certain kind of parallelism — with a nearby utterance, or with the text of the law. In principle, however, any preference that favors the form that is dispreferred by MP will do.

20 It is of course possible that the speaker has no such preference for parallelism, or that he has it, but ranks it below MP. That is why the alternative utterance with both is also felicitous. 
On the status of 'Maximize Presupposition'

\section{Conclusion}

I have shown that there is a construal of MP that can predict infelicities, deal with obviations, predict presuppositional implicatures, and do all of these things in a Gricean way. Specifically, I have argued that MP should neither be construed as a Gricean maxim, nor as a normative rule governing felicity. Instead, it should be construed as 'linguistic preference'-a selfish preference between linguistic forms that speakers happen to have. On this view, the puzzling tension between infelicity and the existence of obviations turns out to fit naturally into a Gricean model of reasoning that construes utterance choice as resulting from an interaction of different pragmatic pressures that may trade off in various ways. The reason that we still can account for infelicities is that the present construal not only allows MP to be defeated, it requires it to be defeated whenever the less-presupposing form is used.

As for the content of the preference, I have adopted a version of Percus' formulation, but it remains to be seen whether this version can be defended against empirical counterarguments pointed out by several authors (the most challenging data, to my mind, is presented by Collins 2016, but see also Sauerland 2008, Singh 2011 and Schlenker 2012). Here, I confine myself to noting that, on the construal advocated in this paper, Lexical MP is immune to a conceptual counterargument raised by Singh (2011):

"As a constraint regulating the semantics/pragmatics interface, [Lexical MP] strikes me as somewhat unnatural. I know of no other principles of semantics/pragmatics that display preferences among LFs that are sensitive not to their semantic or contextual meanings but rather solely to the lexical items contained within them."

In the present context, (20) is not claimed to be motivated by general considerations about cooperative behavior. Instead, MP is simply stipulated as a preference between forms that speakers happen to have, akin to the submaxims of Grice's MAXIM OF MANNER. If construed thusly, there is nothing untoward about making reference, as Percus did, to lexical presuppositions in the formulation of principle.

Almost all assumptions I have made throughout are arguably independently motivated on a Gricean approach to language use (or constituted simplifying assumptions). The only assumption for which this is not true is the stipulation of the MP preference itself: I have given no independent justification for assuming that speakers have such a preference (and that hearers expect them to have it), which may make the stipulation difficult to swallow. But, at present, I see no alternative to swallowing it: The only plausible way to deal with instances of obviation I can see is to derive the effects of MP in a Gricean manner. And the only plausible way I can see to do that is by assuming that MP is a 'linguistic preference'. 


\section{References}

Alonso-Ovalle, Luis, Paula Menéndez-Benito \& Florian Schwarz. 2011. Maximize presupposition and two types of definite competitors. In North East Linguistic Society Conference (NELS) 39, 29-41.

Barker, Chris. 2005. Possessive weak definites. In Ji yung Kim, Yury Lander \& Barbara Partee (eds.), Possessives and Beyond: Semantics and Syntax, 89-113. GLSA Publications.

Bergen, Leon, Noah D. Goodman \& Roger Levy. 2012. That's what she (could have) said: How alternative utterances affect language use. In Naomi Miyake, David Peebles \& Richard P. Cooper (eds.), Cognitive Science Society 34, 120-125. Austin, TX.

Blutner, R. 2000. Some aspects of optimality in natural language interpretation. Journal of Semantics 17(3). 189-216. doi:10.1093/jos/17.3.189.

Chemla, Emmanuel. 2008. An epistemic step for anti-presuppositions. Journal of Semantics 25(2). 141-173. doi:10.1093/jos/ffm017.

Collins, James N. 2016. Reasoning about definiteness in a language without articles. In Mary Moroney, Carol-Rose Little, Jacob Collard \& Dan Burgdorf (eds.), Semantics and Linguistic Theory (SALT) 26, 82-102. LSA and CLC Publications. doi:10.3765/salt.v26i0.3821.

Degen, Judith \& Michael Franke. 2012. Optimal reasoning about referential expressions. In Sarah Brown-Schmidt, Jonathan Ginzburg \& Staffan Larsson (eds.), The semantics and pragmatics of dialogue (SemDial: SeineDial), 2-11. Université Paris-Diderot (Paris 7), Paris Sorbonne-Cité.

Eckardt, Regine. 2007. Licensing 'or'. In Sauerland Uli \& Penka Stateva (eds.), Presupposition and Implicature in Compositional Semantics, 34-70. New York, NY: Palgrave Macmillan. doi:10.1057/9780230210752_3.

Frank, Michael C. \& Noah D. Goodman. 2012. Predicting pragmatic reasoning in language games. Science 336(6084). 998. doi:10.1126/science.1218633.

Franke, Michael. 2009. Signal to act: Game theory and pragmatics. Amsterdam, The Netherlands: Universiteit van Amsterdam PhD dissertation.

Gazdar, Gerald. 1979. Pragmatics: Implicature, Presupposition and Logical Form. New York: Academic Press.

Geurts, Bart. 2010. Quantity implicatures. Cambridge/New York: Cambridge University Press.

Grice, Herbert Paul. 1975. Logic and conversation. In Peter Cole \& Jerry L. Morgan (eds.), Speech Acts Syntax and Semantics 3, 41-58. Academic Press.

Heim, Irene. 1991. Artikel und Definitheit [Articles and definiteness]. In A. von Stechow \& D. Wunderlich (eds.), Semantik: Ein internationales Handbuch der zeitgenössischen Forschung, 487-535. Berlin: de Gruyter. 
On the status of 'Maximize Presupposition'

Horn, Laurence R. 1972. On the semantic properties of logical operators in English. Los Angeles, CA: University of California, Los Angeles PhD dissertation.

Horn, Laurence R. 1984. Towards a new taxonomy of pragmatic inference: Q-based and R-based implicature. In Meaning, Form, and Use in Context: Linguistic Applications, 11-42. Washington, DC: Georgetown University Press.

Horn, Laurence R. 1989. A Natural History of Negation. Chicago, IL: Chicago University Press. Page numbers refer to the 2001 CSLI Publications reprint.

Horn, Laurence R. 2000. From if to iff: Conditional perfection as pragmatic strengthening. Journal of Pragmatics 32. 289-326. doi:10.1016/s0378-2166(99)00053-3.

Jäger, Gerhard. 2007. Game dynamics connects semantics and pragmatics. In Ahti-Veikko Pietarinen (ed.), Game Theory and Linguistic Meaning, 89-102. Amsterdam/New York: Elsevier. doi:10.1163/9780080548524_008.

Lauer, Sven. 2013. Towards a dynamic pragmatics. Stanford, CA: Stanford University $\mathrm{PhD}$ dissertation.

Lauer, Sven. 2014. Mandatory implicatures in Gricean pragmatics. In N. D. Goodman, Michael Franke \& Judith Degen (eds.), Formal \& Experimental Pragmatics, 21-28. Tübingen.

Leahy, Brian. 2014. On presuppositional implicature. Topoi 35(1). 83-91. doi:10.1007/s11245-014-9281-4.

Lewis, David. 1979. Scorekeeping in a language game. Journal of Philosophical Logic 8(1). 339-359. doi:10.1002/9780470758335.ch6.

Mandelkern, Matthew Aaron. 2016. Dissatisfaction theory. In Mary Moroney, Carol-Rose Little, Jacob Collard \& Dan Burgdorf (eds.), Semantics and Linguistic Theory (SALT) 26, 391-416. LSA and CLC Publications. doi:10.3765/salt.v26i0.3804.

Percus, Orin. 2006. Antipresuppositions. In Ayumi Ueyama (ed.), Theoretical and Empirical Studies of Reference and Anaphora, 52-73. Japan Society for the Promotion of Science.

Potts, Christopher, Daniel Lassiter, Roger Levy \& Michael C. Frank. 2015. Embedded implicatures as pragmatic inferences under compositional lexical uncertainty. doi:10.1093/jos/ffv012. To appear in Journal of Semantics.

Potts, Christopher \& Roger Levy. 2015. Negotiating lexical uncertainty and speaker expertise with disjunction. In Anna E. Jurgensen, Hannah Sande, Spencer Lamoureux, Kenny Baclawski \& Alison Zerbe (eds.), Berkeley Linguistics Society $(B L S)$ 41, 417-445. Berkeley, CA: Berkeley Linguistics Society. doi:10.20354/b4414110013.

Prince, Alan \& Paul Smolensky. 1993. Optimality theory: Constraint interaction in generative grammar. Technical Report 2 Rutgers University Center for Cognitive Science. doi:10.1002/9780470756171.ch1.

Rawlins, Kyle. 2005. Possessive definites and the definite article. Ms., UC Santa 
Cruz.

Rawlins, Kyle. 2006. Possessive antecedents to donkey pronouns. In Donald Baumer, David Montero \& Michael Scanlon (eds.), West Coast Conference on Formal Linguistics (WCCFL) 25, 337-345. Cascadilla Proceedings Project. http://www.lingref.com/cpp/wccfl/25/paper1466.pdf.

Sauerland, Uli. 2002. The present tense is vacuous. Snippets 6. http://www.ledonline. it/snippets/allegati/snippets6004.pdf.

Sauerland, Uli. 2003. Implicated presuppositions. Handout for a talk presented at the University of Milan Bicocca.

Sauerland, Uli. 2006. On the semantic markedness of phi features. In Daniel Habour, David Adger \& Susana Béjar (eds.), Phi-theory: Phi Features Across Modules and Interfaces 57-82, Oxford University Press.

Sauerland, Uli. 2008. Implicated presuppositions. In Anita Steube (ed.), The discourse potential of underspecified structures, 581-600. Berlin: Mouton De Gruyter. doi:10.1515/9783110209303.4.581.

Sauerland, Uli, Jan Andersen \& Kazuko Yatsushiro. 2005. The plural is semantically unmarked. In Stephan Kepser \& Marga Reis (eds.), Linguistic Evidence: Empirical, Theoretical, and Computational Perspectives, 413-434. Mouton de Gruyter. doi:10.1515/9783110197549.413.

Schlenker, Philippe. 2005. The lazy Frenchman's approach to the subjunctive: Speculations on reference to worlds and semantics defaults in the analysis of mood. In Twan Geerts, Ivo van Ginneken \& Haike Jacobs (eds.), Romance Languages and Linguistic Theory 2003: Selected papers from 'Going Romance' 2003, 269-309. John Benjamins. doi:10.1075/cilt.270.15sch.

Schlenker, Philippe. 2012. Maximize presuposition and Gricean reasoning. Natural Language Semantics 20(4). 391-429. doi:10.1007/s11050-012-9085-2.

Singh, Raj. 2011. Maximize Presupposition! and local contexts. Natural Language Semantics 19(2). 149-168. doi:10.1007/s11050-010-9066-2.

Spector, Benjamin. 2014. Global positive polarity items and obligatory exhaustivity. Semantics and Pragmatics 11(7). 1-61. doi:10.3765/sp.7.11.

Stalnaker, Robert. 1973. Presuppositions. Journal of Philosophical Logic 2. 447457. doi:10.1007/bf00262951.

Stalnaker, Robert. 1974. Pragmatic presupposition. In Milton Munitz \& Peter Unger (eds.), Semantics and Philosphy, 197-213. New York: New York University Press. 
On the status of 'Maximize Presupposition'

Sven lauer

Zukunftskolleg / Department of Linguistics

University of Konstanz

Box 216

78457 Konstanz

Germany

sven@sven-lauer.net 